\title{
Markers of de novo lipogenesis in adipose tissue: associations with small adipocytes and insulin sensitivity in humans
}

\author{
R. Roberts • L. Hodson • A. L. Dennis • M. J. Neville • \\ S. M. Humphreys • K. E. Harnden • K. J. Micklem • \\ K. N. Frayn
}

Received: 16 December 2008 / Accepted: 30 January 2009/Published online: 28 February 2009

(C) Springer-Verlag 2009

\begin{abstract}
Aims/hypothesis Previous studies have shown relationships between fatty acid ratios in adipose tissue triacylglycerol (TG), adipocyte size and measures of insulin sensitivity. We hypothesised that variations in adipose tissue de novo lipogenesis (DNL) in relation to adiposity might explain some of these observations.

Methods In a cross-sectional study, subcutaneous abdominal adipose tissue biopsies from 59 people were examined in relation to fasting and post-glucose insulin sensitivity. Adipocyte size, TG fatty acid composition and mRNA expression of lipogenic genes were determined.

Results We found strong positive relationships between adipose tissue TG content of the fatty acids myristic acid (14:0) and stearic acid (18:0) with insulin sensitivity (HOMA model) $(p<0.01$ for each), and inverse relation-
\end{abstract}

Electronic supplementary material The online version of this article (doi:10.1007/s00125-009-1300-4) contains supplementary material, which is available to authorised users.

R. Roberts · L. Hodson • A. L. Dennis · M. J. Neville •

S. M. Humphreys $\cdot$ K. E. Harnden $\cdot$ K. N. Frayn $(\bowtie)$

Oxford Centre for Diabetes, Endocrinology and Metabolism,

University of Oxford, Churchill Hospital,

Oxford OX3 7LJ, UK

e-mail: keith.frayn@oxlip.ox.ac.uk

\section{K. J. Micklem}

The Nuffield Department of Clinical Laboratory Sciences,

University of Oxford, John Radcliffe Hospital,

Oxford, UK

\section{A. L. Dennis $\cdot$ K. N. Frayn}

NIHR Oxford Biomedical Research Centre, University of Oxford, Churchill Hospital,

Oxford, UK ships with adipocyte size ( $p<0.01, p<0.05$, respectively). Variation in 18:0 content was the determinant of the adipose tissue TG 18:1 n-9/18:0 ratio, which correlated negatively with insulin sensitivity $(p<0.01)$, as observed previously. Adipose tissue 18:0 content correlated positively with the mRNA expression of lipogenic genes (e.g. $F A S N, p<0.01$ ). Lipogenic gene expression (a composite measure derived from principal components analysis) was inversely correlated with adipocyte cell size $(p<0.001)$. There was no relationship between dietary saturated fatty acid intake and adipose tissue 18:0 content.

Conclusions/interpretation Our data suggest a physiological mechanism whereby DNL is downregulated as adipocytes expand. Taken together with other data, they also suggest that hepatic and adipose tissue DNL are not regulated in parallel. We also confirm a strong relationship between small adipocytes and insulin sensitivity, which is independent of BMI.

Keywords Adipocytes · de novo lipogenesis · dietary fatty acids · insulin sensitivity · saturated fatty acids $\cdot$ stearic acid . stearoyl-CoA desaturase $\cdot$ triacylglycerol

\begin{tabular}{|c|c|}
\hline \multicolumn{2}{|c|}{ Abbreviations } \\
\hline DNL & De novo lipogenesis \\
\hline FA & Fatty acid \\
\hline HOMA-IS & $\begin{array}{l}\text { Homeostatic model assessment } \\
\text { of insulin sensitivity }\end{array}$ \\
\hline IS & Insulin sensitivity \\
\hline $\mathrm{PC} 1$ & $\begin{array}{l}\text { First principal component of gene } \\
\text { expression data }\end{array}$ \\
\hline PCA & Principal components analysis \\
\hline SCD & Stearoyl-CoA desaturase \\
\hline TG & Triacylglycerol \\
\hline
\end{tabular}




\section{Introduction}

Obesity and insulin resistance are increasingly prevalent risk factors for type 2 diabetes and CHD. Whilst total fat mass and its distribution are undoubtedly important, it is becoming clear that the size of the adipocyte is a more subtle predictor of adverse metabolic status. It has been recognised for many years that there is a relationship between small adipocyte size and whole-body insulin sensitivity (IS) in humans [1-3]. In rats, adipocyte hypertrophy is strongly linked to peripheral insulin resistance, independently of total body fat [4]. Human adipocyte size is an independent predictor of the development of type 2 diabetes [2]. Thus, an understanding of the mechanisms that govern adipocyte size is important.

Enlargement of adipocytes might arise from increased fat deposition (lipogenesis), either from fatty acids (FAs) taken up from plasma or from those synthesised de novo (de novo lipogenesis $[\mathrm{DNL}])$. The literature regarding the relationship between cell size and lipogenesis is not consistent. In vitro experiments in rats and human cells report increased DNL in large cells $[5,6]$, whereas other rat studies have reported decreased insulin-enhanced DNL from glucose [7, 8]. Caution should be exercised in extrapolating results from rat studies, as the lipogenic capacity of adipose tissue in humans is lower than in rats [9]. Nevertheless, it is clear that DNL does operate in human adipose tissue [10, 11], although it is not the major pathway for fat deposition. Expression of several lipogenic genes, principally $F A S N$, has been shown to be higher in smaller human adipocytes [12, 13]. Recently, however, it has been proposed that increased energy intake and accumulation of body fat is linked to increased expression of the lipogenic gene FASN in adipose tissue [14].

Closely related to DNL is the process of FA desaturation. Currently there is interest in the expression and effects of the enzyme stearoyl-CoA desaturase (SCD), as reflected in FA ratios in plasma [15] or in adipose tissue [16], in relation to insulin status. SCD is regulated in parallel with the pathway of DNL [17], and is responsible for desaturating palmitic acid (16:0) and stearic acid (18:0) to palmitoleic (16:1 n-7) and oleic acid (18:1 n-9), respectively. Individuals with a high ratio of 18:1 $n-9 / 18: 0$ in adipose tissue triacylglycerol (TG) are more likely to be insulin resistant [16]. There is little evidence in the literature linking adipocyte FA composition to cell size in humans, although greater $n-6$ and $n-3$ polyunsaturated FA content is associated with smaller adipocytes in subcutaneous adipose tissue [18].

Our aim was to investigate adipocyte cell size in relation to IS and adipocyte TG FA composition in normally fed humans. We wanted to test the hypothesis that increased DNL might drive fat cell expansion, in parallel with whole- body insulin resistance. We set out to test this hypothesis in a cross-sectional study by examining the expression of genes in adipose tissue which are associated with lipogenesis, and by investigating the TG FA composition in cells of different sizes. In order to understand the origins of variation in adipose tissue TG FA composition between people, we have also conducted dietary analysis.

\section{Methods}

We recruited 59 healthy individuals with a range of adiposity (BMI $20-37 \mathrm{~kg} / \mathrm{m}^{2}$ ) to take part in a crosssectional metabolic investigation. All participants gave written informed consent and the study was approved by the Oxfordshire Clinical Research Ethics Committee.

They were studied at rest, following an overnight fast, after refraining from strenuous exercise and alcohol for $24 \mathrm{~h}$. A cannula was inserted retrogradely into a distal forearm vein and kept patent by a continuous slow infusion of saline $(\mathrm{NaCl} 9 \mathrm{~g} / \mathrm{l})$. The lower part of the forearm was heated to provide arterialised blood samples. Three fasting samples were taken every $30 \mathrm{~min}$ and a further six samples were taken after ingestion of $75 \mathrm{~g}$ glucose, for $2 \mathrm{~h}$. The oral glucose challenge provided a dynamic measure of IS as described below. Blood samples were taken into heparinised syringes and plasma separated rapidly by centrifugation at $4^{\circ} \mathrm{C}$ and stored at $-20^{\circ} \mathrm{C}$ for later analysis.

A subcutaneous abdominal adipose needle biopsy was taken at the end of the study as described previously [19]. The biopsy was washed with saline. A portion was placed in $4 \%(\mathrm{wt} / \mathrm{vol}$.) formalin, and the remaining tissue placed in TRI Reagent (Applied Biosystems, Warrington, UK) and homogenised immediately in a ball mill homogeniser (MM301 Mixer Mill; Retsch UK, Leeds, UK) with $6 \mathrm{~mm}$ cone ball-bearings.

\section{Sample analyses}

Biochemical analyses Plasma glucose, TG and NEFA concentrations were determined enzymatically (glucose and TG; Instrumentation Laboratory, Warrington, UK: NEFA C kit; Wako Chemicals, Neuss, Germany) using an ILab 600 Multianalyser (Instrumentation Laboratory). Plasma insulin concentrations were determined by RIA using a commercially available kit (Linco Research, St Charles, MO, USA).

Cell size analysis A histological method was used for adipocyte size analysis, based on the method of Chen and Farese [20]. This gives an average cell diameter for comparison purposes between samples. Adipose tissue was embedded in paraffin within 2 weeks of the biopsy, 
and cut into $4 \mu \mathrm{m}$ sections. The sections were de-waxed and stained with haematoxylin. A low-power image was captured using an Olympus C-4040 Zoom digital camera (Olympus UK, London, UK) and the images analysed using Adobe Photoshop CS2 9.0.2 (Adobe Systems, San Jose, CA, USA) and Image Processing Tool Kit (Reindeer Games, Gainesville, FL, USA). Using a script (Photoshop Action) the calibrated images were processed to minimise background variations and converted to a binary image by selecting a fixed proportion of the darkest pixels. This image was skeletonised and the areas of cell profiles were measured. Cross-sectional areas were calculated as $\mu \mathrm{m}^{2}$. Results were directly loaded into a spreadsheet program (Excel; Microsoft, Redmond, WA, USA) for analysis. Values $<50 \mu \mathrm{m}^{2}$ were assumed to represent artefacts from the image-conversion process and were excluded from analysis. A minimum of 200 cell areas were recorded per individual.

There are many methods for analysing adipocyte size, some of which are discussed by Chen and Farese [20], along with validation of this particular method. Smith et al. [21] compared a tissue section method very similar to that of Chen and Farese with collagenase digestion, and obtained very similar results. The strength of the correlation that we observed between cell size and IS (see the Results) was almost identical to that observed in another crosssectional study, in which an independent method for cell size analysis was used [2].

Gene expression The homogenised biopsy samples were diluted in TRI Reagent to $1 \mathrm{ml} / 100 \mathrm{mg}$ of tissue and centrifuged at $9,500 \times \mathrm{g}$ for $30 \mathrm{~min}$ at $4^{\circ} \mathrm{C}$. The lipid layer was removed and stored at $-20^{\circ} \mathrm{C}$ for later FA analysis.

Adipose tissue total RNA was isolated using a mirVana miRNA isolation kit (Applied Biosystems), following the manufacturer's instructions. Total RNA was then treated with DNAase (Applied Biosystems) and cDNA was synthesised using a high-capacity cDNA reverse transcription kit (Applied Biosystems).

The mRNA expressions of ACACA, ACLY, DGAT1, DGAT2, ELOVL6, FASN, PPARG1, PPARG2 and SCD were quantified by real-time PCR using TaqMan gene expression assays (Assay-on-demand; Applied Biosystems) and normalised for expression for the housekeeping genes, PPIA, RPLP0 and PGK1, using the $\Delta \Delta \mathrm{C}_{\mathrm{t}}$ method [22]. Assay identification details for the genes are given in the Electronic supplementary material (ESM) Table 1. Standards and samples were analysed in quadruplicate and reaction efficiency was calculated using a standard curve for each assay by serially diluting a pool of all cDNAs generated. Amplification and detection were performed using an ABI PRISM 7900HT sequence detection system (Applied Biosystems) using standard ABI RT qPCR thermal cycling conditions. Further details have been given previously [23].

FA analyses The FA composition of plasma NEFA and of adipose tissue TG was analysed. For the latter, a sample (approximately $200 \mu \mathrm{l}$ ) of the lipid layer from the RNA isolation step was used to determine TG FA composition [24]. Total lipids were extracted, and FA methyl esters prepared from NEFA or TG fractions, respectively, as previously described [25]. FA composition ( $\mu \mathrm{mol} / 100 \mu \mathrm{mol}$ total FA) was determined by GC as previously described [26]. For TG analysis, an internal standard containing 15:0 was used, which precluded measurement of the proportion of 15:0 directly in adipose tissue TG.

Dietary analyses All foods and beverages consumed on three representative non-consecutive days (2 weeks/1 weekend) over a 2 week period prior to coming in for the study day were weighed or estimated and recorded into food diaries. The energy and nutrient composition of the diets was calculated using the food composition data from the Microdiet 2 program (Downlee Systems, Chapel-en-leFrith, UK).

\section{Calculations and statistical analysis}

Fasting IS (HOMA-IS) was calculated from fasting glucose and insulin concentrations as the reciprocal of the HOMA of insulin resistance [27].

Post-glucose IS was calculated as follows: $I S I($ gly $)=$ $2 /[(I N S p \times G L Y p)+1]$, where INSp and GLYp are insulin and glucose AUCs, respectively, over $2 \mathrm{~h}$ after glucose ingestion, expressed relative to average values from the group of individuals [28].

FA ratios were calculated as proxy measures of elongation and desaturation activity (Fig. 1) [16], as follows: 18:0/16:0 (proxy for FA elongase activity); 16:1 $n-7 / 16: 0$ and 18:1 n-9/18:0 (proxy for SCD activity).

Data were analysed using SPSS for Windows v11 (SPSS UK, Chertsey, UK). The normal distribution of the continuous variables was examined with a Shapiro-Wilk test, and skewed variables were $\log _{10}$ transformed to normalise or approximately normalise the distribution.

To determine how the variables in this study related to one another, we performed a principal components analysis (PCA). This is a multivariate statistical method by which a dataset can be represented by a few new variables (called 'principal components'), which are linear combinations of the original variables. This analysis was applied to both the metabolic data (including the biochemical analysis, the FA composition, the adipocyte cell size data, BMI and HOMAIS values) and the data for gene expression. Only the results 


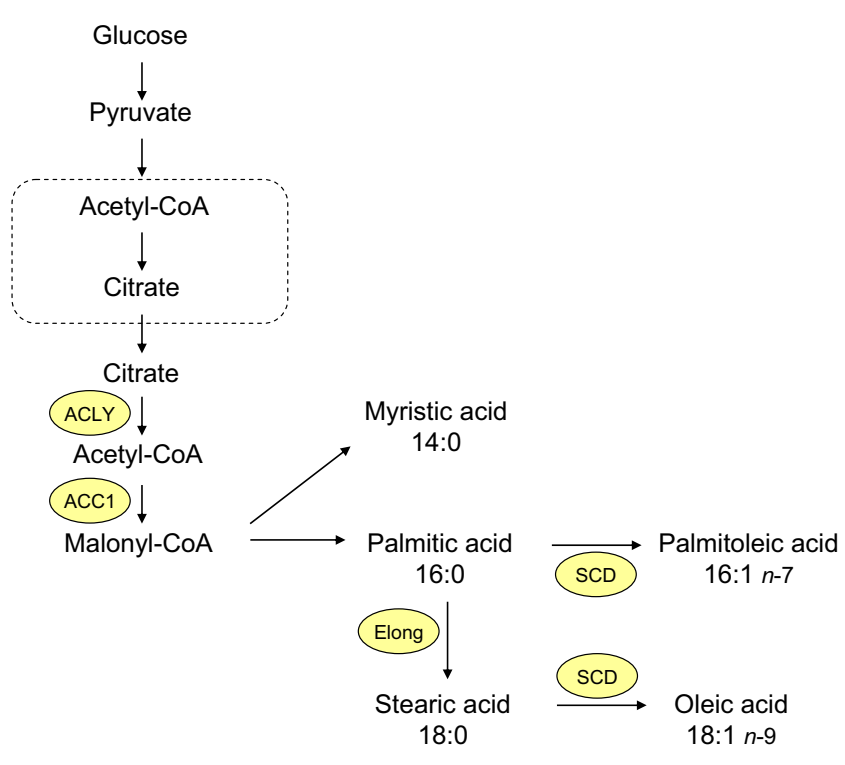

Fig. 1 Pathway of DNL. The dotted line represents a mitochondrion. ACC1, acetyl-coenzyme A carboxylase alpha; ACLY, ATP citrate lyase; Elong, elongation; SCD, stearoyl-coenzyme A desaturase

for the gene expression are included in the paper, although the 'metabolic PCA' influenced our analysis of the data. The $\Delta \Delta \mathrm{C}_{\mathrm{t}}$ values for the gene expression were entered. The resulting factor patterns were interpreted using factor loadings, and the most powerful factors (eigenvalues $>1.0$ ) were retained for further analysis. Factor loadings $>0.4$ were considered to be of importance.

In order to understand variation in FA ratios, as described under Results, we generated random values for mol\% of the FAs 18:1 n-9 and 16:0, between the maximum and minimum values from the dataset, using the RANDBETWEEN function in Excel.

\section{Results}

Participants

Table 1 details the volunteers' characteristics. From the results of the oral glucose administration, 40 individuals were found to have normal glucose tolerance and 19 to have impaired glucose tolerance [29].

No age or sex effect was seen in any analyses; therefore results are presented as a single group and not divided by sex, although men and women are distinguished in the figures.

Insulin sensitivity

The fasting IS index, HOMA-IS, was negatively correlated with adipocyte cell size $\left(r=-0.57, p=1.4 \times 10^{-5}\right)$ (Fig. 2a), as was post-glucose IS ( $r=-0.39, p=0.005)$ (Fig. 2b). This relationship remained significant for both indices when controlling for BMI $(r=-0.37, p=0.01$ and $r=-0.30, p=0.04$, for HOMA-IS and post-glucose IS, respectively).

When we examined the FA composition of adipose tissue TG, we observed that the proportions of 14:0 and 18.0 (mol\% of adipose tissue TG) correlated with HOMAIS and post-glucose IS (Table 2, Fig. 2c, d). Adipose tissue TG 18:0/16.0 and 18:1 n-9/18:0 ratios, but not the $16: 1 n-7 /$ 16:0 ratio, also correlated strongly with the indices of IS (Table 2). The 14:0, 16:0 and 18:0 content, as well as the 18:0/16.0 and 18:1 n-9/18:0 ratios, were also correlated with BMI (Table 2). In a partial correlation controlling for BMI, HOMA-IS remained positively significantly correlated with 14:0, 18:0 and 18:0/16:0 ratio, and negatively with 18:1 n-9/18:0 ratio. Post-glucose IS remained significantly positively correlated with $18: 0$ and 18:0/16.0, and negatively with 18:1 n-9/18:0. The adipose tissue content of $14: 0$ and 18:0, and the 18:0/16:0 ratio, correlated negatively, and the 18:1 n-9/18:0 ratio positively, with adipocyte cell size (Table 2, Fig. 2e, f).

The relationship of the ratios 18:0/16:0 and 18:1 n-9/ 18:0 with IS appeared to be determined by the proportion of adipose tissue TG 18:0. To test this, random values for mol $\%$ for the FAs 16:0 and 18:1 n-9 were generated, and new ratios for 18:0/16:0 and 18:1 n-9/18:0 were calculated, called below 18:0/16:0 RAND and 18:1 $n-9_{\text {RAND }} / 18: 0$, respectively. Correlations were performed against HOMAIS and the relationships remained equally strong (18:0/ 16:0 ${ }_{\text {RAND }}$ and HOMA-IS, $r=0.64, p<0.001 ; 18: 1 n-9_{\mathrm{RAND}} /$ 18:0 and HOMA-IS, $r=-0.51, p<0.001)$.

Gene expression, FA composition and cell size

Correlation matrix and PCA for gene expression Genes involved with the DNL pathway strongly correlated with each other (Table 3).

Table 1 Characteristics of study volunteers

\begin{tabular}{lc}
\hline Variable & Value \\
\hline Age (years) & $44(19-58)$ \\
BMI $\left(\mathrm{kg} / \mathrm{m}^{2}\right)$ & $27(20-37)$ \\
Fasting glucose $(\mathrm{mmol} / \mathrm{l})$ & $5.0(4.0-6.1)$ \\
Fasting insulin $(\mathrm{pmol} / \mathrm{l})$ & $54.6(6.0-321.0)$ \\
Fasting NEFA $(\mu \mathrm{mol} / \mathrm{l})$ & $492(224-1,034)$ \\
Fasting TG $(\mathrm{mmol} / \mathrm{l})$ & $1.0(0.4-3.2)$ \\
Cholesterol $(\mathrm{mmol} / \mathrm{l})$ & $4.5(3.3-7.2)$ \\
HDL-cholesterol $(\mathrm{mmol} / \mathrm{l})$ & $1.1(0.6-1.9)$ \\
Resting heart rate $(\mathrm{beats}$ per min) & $60(44-86)$ \\
Systolic BP $(\mathrm{mmHg})$ & $110(89-149)$ \\
Diastolic BP $(\mathrm{mmHg})$ & $72(58-99)$ \\
\hline
\end{tabular}

Data are medians (range) 

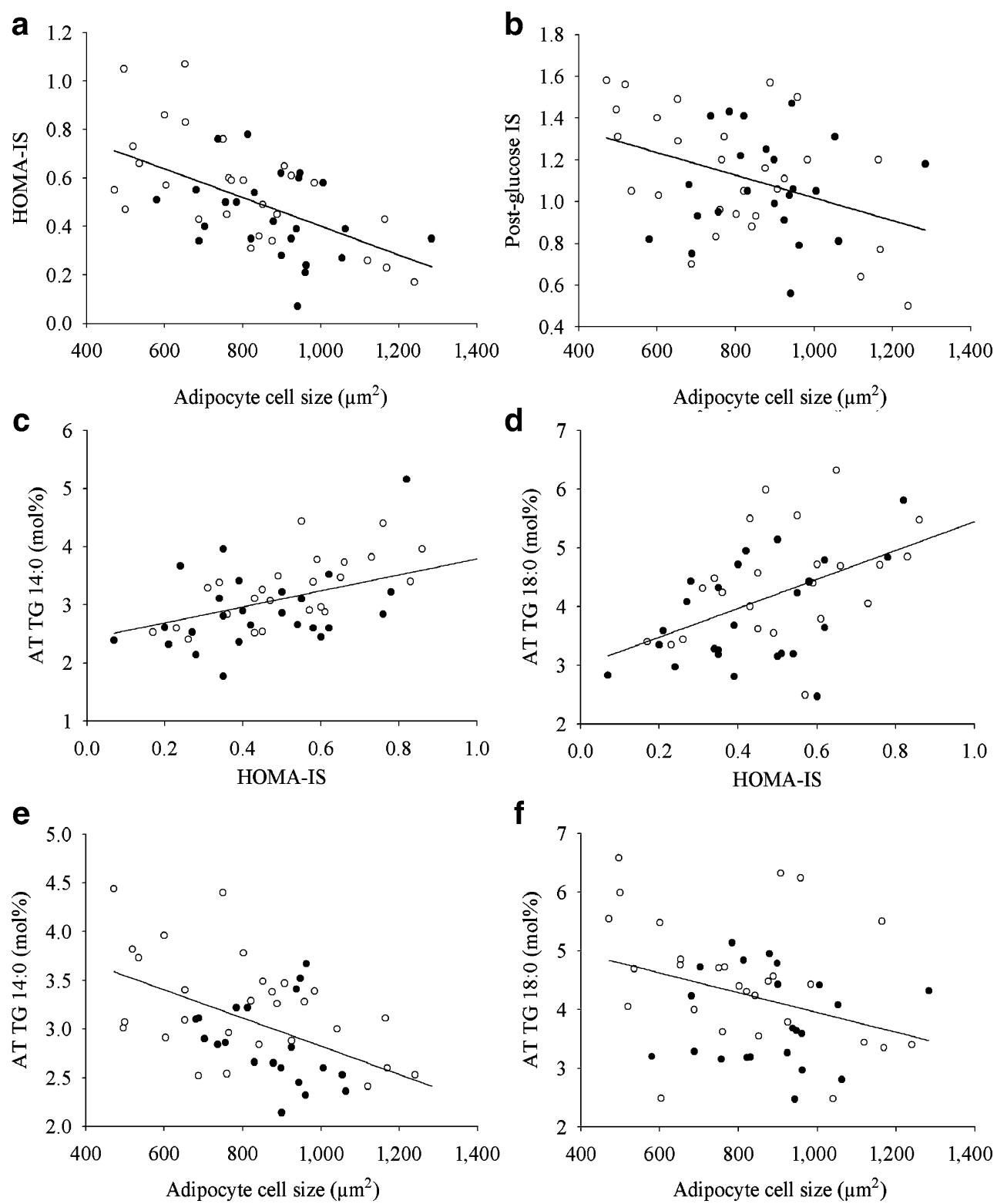

Fig. 2 Relationships between adipocyte cell size, TG FA content and IS in men (black circles) and women (white circles). Adipocyte cell size was related to fasting IS (HOMA-IS) (a) and post-glucose IS (b). HOMA-IS was related to adipose tissue (AT) TG content of 14:0 (c)

and 18:0 (d). Adipocyte cell size was related to AT TG 14:0 (e) and 18:0 (f). Results of statistical analyses are given in the text and in Table 2

Table 2 Correlation coefficients for adipose tissue TG FAs and the relationships with HOMA-IS, post-glucose IS, BMI and adipocyte cell size

\begin{tabular}{|c|c|c|c|c|c|c|c|c|}
\hline \multirow[t]{2}{*}{ Variable } & \multicolumn{8}{|c|}{ Fatty acid } \\
\hline & $14: 0$ & $16: 0$ & $16: 1 n-7$ & $18: 0$ & $18: 1$ & 18:0/16:0 & $16: 1 n-7 / 16: 0$ & $18: 1 n-9 / 18: 0$ \\
\hline HOMA-IS & $0.45^{\mathrm{a}}$ & $-0.28^{\mathrm{b}}$ & 0.03 & $0.54^{\mathrm{a}}$ & -0.05 & $0.59^{\mathrm{a}}$ & 0.11 & $-0.51^{\mathrm{a}}$ \\
\hline Post-glucose IS & $0.34^{\mathrm{b}}$ & -0.14 & -0.11 & $0.57^{\mathrm{a}}$ & -0.00 & $0.57^{\mathrm{a}}$ & -0.07 & $-0.48^{\mathrm{a}}$ \\
\hline BMI & $-0.37^{\mathrm{a}}$ & $0.28^{\mathrm{b}}$ & -0.05 & $-0.45^{\mathrm{a}}$ & 0.04 & $-0.50^{\mathrm{a}}$ & -0.13 & $0.40^{\mathrm{a}}$ \\
\hline Cell size & $-0.37^{\mathrm{a}}$ & 0.24 & 0.07 & $-0.33^{\mathrm{b}}$ & 0.10 & $-0.38^{\mathrm{a}}$ & 0.02 & $0.39^{\mathrm{a}}$ \\
\hline
\end{tabular}

${ }^{\mathrm{a}} p<0.01,{ }^{\mathrm{b}} p<0.05$; Pearson correlations 
Table 3 Correlation coefficients between $\Delta \Delta$ values of lipogenic gene expression in abdominal subcutaneous adipose tissue

The full names for genes are given in ESM Table 1. PPARG1 and $P P A R G 2$ are different transcripts produced from the $P P A R G$ gene

${ }^{\mathrm{a}} p<0.01,{ }^{\mathrm{b}} p<0.05$; Pearson correlations

\begin{tabular}{|c|c|c|c|c|c|c|c|c|}
\hline \multirow[t]{2}{*}{ Gene } & \multicolumn{8}{|l|}{ Gene } \\
\hline & $A C L Y$ & $A C A C A$ & $F A S N$ & ELOVL6 & $S C D$ & PPARG1 & PPARG2 & $D G A T 1$ \\
\hline \multicolumn{9}{|l|}{$A C L Y$} \\
\hline$A C A C A$ & $0.90^{\mathrm{a}}$ & & & & & & & \\
\hline$F A S N$ & $0.82^{\mathrm{a}}$ & $0.79^{\mathrm{a}}$ & & & & & & \\
\hline ELOVL6 & $0.80^{\mathrm{a}}$ & $0.73^{\mathrm{a}}$ & $0.59^{\mathrm{a}}$ & & & & & \\
\hline$S C D$ & $0.75^{\mathrm{a}}$ & $0.82^{\mathrm{a}}$ & $0.69^{\mathrm{a}}$ & $0.50^{\mathrm{a}}$ & & & & \\
\hline PPARG1 & $0.47^{\mathrm{a}}$ & $0.50^{\mathrm{a}}$ & $0.51^{\mathrm{a}}$ & $0.38^{\mathrm{a}}$ & $0.45^{\mathrm{a}}$ & & & \\
\hline PPARG2 & $0.40^{\mathrm{a}}$ & $0.45^{\mathrm{a}}$ & $0.46^{\mathrm{a}}$ & $0.33^{\mathrm{b}}$ & $0.40^{\mathrm{a}}$ & $0.92^{\mathrm{a}}$ & & \\
\hline$D G A T 1$ & $0.45^{\mathrm{a}}$ & $0.50^{\mathrm{a}}$ & $0.53^{\mathrm{a}}$ & $0.32^{\mathrm{b}}$ & $0.58^{\mathrm{a}}$ & $0.33^{\mathrm{b}}$ & $0.35^{\mathrm{b}}$ & \\
\hline DGAT2 & $0.76^{\mathrm{a}}$ & $0.72^{\mathrm{a}}$ & $0.61^{\mathrm{a}}$ & $0.72^{\mathrm{a}}$ & $0.63^{\mathrm{a}}$ & 0.25 & 0.24 & $0.52^{\mathrm{a}}$ \\
\hline
\end{tabular}

In a PCA of $\triangle \triangle \mathrm{C}_{\mathrm{t}}$ values of lipogenic gene expression (ACLY, ACACA, FASN, ELOVL6, SCD, PPARG1, PPARG2, $D G A T 1$ and $D G A T 2$ ), maximum factor loadings all occurred in the first principal component of gene expression data (PC1) (which could be seen as a composite marker of expression of genes involved in DNL), hereafter known as $\mathrm{PC} 1_{\text {genes }}$, with values between 0.6 and 1.0 (ESM Table 1). $\mathrm{PC} 1_{\text {genes }}$ is therefore effectively a composite measure of the expression of the genes involved in DNL. HOMA-IS was positively associated with $\mathrm{PC}_{\text {genes }}(r=0.34, p=0.02)$ whereas BMI and cell size were negatively associated with PC $1_{\text {genes }}(r=-0.63, p<0.001$ and $r=-0.55, p<0.001$, respectively) (Fig. 3). The relationship with adipocyte cell size remained significant after partial correlation controlling for BMI $(p=0.01)$. HOMA-IS did not significantly correlate with $\mathrm{PC} 1_{\text {genes }}$ after partial correlation controlling for either BMI or adipocyte cell size.

There were no correlations between expression levels of the three housekeeping genes PPIA, RPLPO and PGK1 and measures of the FA composition of adipose tissue TG. However, the expression levels of these three genes were highly inter-correlated $(r=0.93-0.98, p<0.001)$.

Relationship of SCD expression with FA ratios Expression of SCD did not correlate with the proxy markers of SCD activity, i.e. adipose tissue FA ratios 16:1 n-7/16:0 and 18:1 n-9/18:0 (Table 4). Also, SCD expression did not correlate with adipose tissue TG 16:0, 16:1 n-7, 18:0 or 18:1 n-9 mol\%. Both $\mathrm{PC} 1_{\text {genes }}$ and the expression of $F A S N$ were associated with the adipose tissue TG FA ratios 18:1 n-9/18:0 and 18:0/16:0, as well as with 18:0 mol\% (Table 4). These correlations were repeated with randomly generated 18:1 $n-9$ and 16:0 values in the ratios, and the relationships remained significant ( $\mathrm{PC} 1_{\text {genes, }} p=0.003$ and $p=0.01$, respectively; FASN, $p=0.001$ and $p=0.05$, respectively), implying that variation in the 18:0 content was the important determinant of variations in the ratios.
Relationship of adipose composition to diet

The percentage contribution of dietary polyunsaturated FAs to total energy intake correlated positively with $18: 2$ $n-6 \mathrm{~mol} \%$ in the TG fraction in adipose tissue $(r=0.42$, $p=0.002)$. No correlation, however, was seen with saturated

a

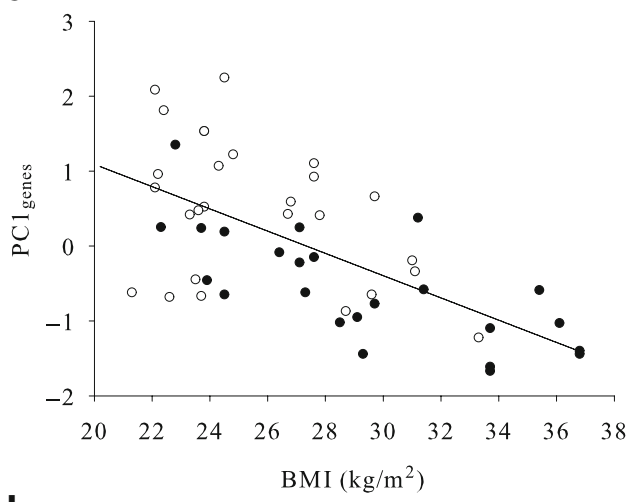

b

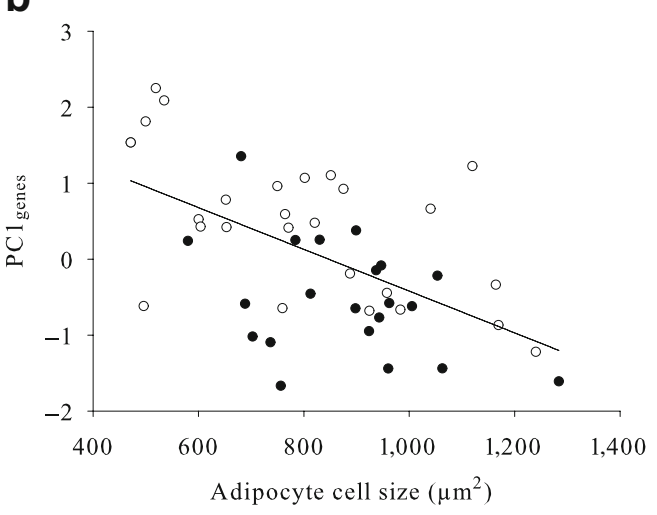

Fig. 3 Relationships with expression of lipogenic genes in adipose tissue. Data are shown for men (black circles) and women (white circles). Expression of DNL genes in adipose tissue was related to BMI (a) and adipocyte cell size (b). Results of statistical analyses are given in the text 
Table 4 Relationship of lipogenic gene expression with FA ratios and $\mathrm{FA} \mathrm{mol} \%$ in adipose tissue TG

The full names for genes are given in ESM Table 1

${ }^{\mathrm{a}} p<0.01,{ }^{\mathrm{b}} p<0.05$; Pearson correlations

\begin{tabular}{lccccccc}
\hline Gene & \multicolumn{1}{l}{ Fatty acid } \\
\cline { 2 - 7 } & $16: 1 n-7 / 16: 0$ & $18: 1 n-9 / 18: 0$ & $18: 0 / 16: 0$ & $16: 0$ & $16: 1 n-7$ & $18: 0$ & $18: 1 n-9$ \\
\hline$S C D$ & 0.25 & -0.17 & 0.17 & -0.12 & 0.25 & 0.17 & -0.16 \\
ELOVL6 & -0.03 & -0.31 & 0.20 & -0.02 & 0.04 & 0.21 & $-0.30^{\mathrm{b}}$ \\
FASN & -0.07 & $-0.40^{\mathrm{a}}$ & $0.42^{\mathrm{a}}$ & -0.08 & -0.05 & $0.45^{\mathrm{a}}$ & -0.17 \\
PC1 & 0.05 & $-0.37^{\mathrm{a}}$ & $0.32^{\mathrm{b}}$ & -0.14 & 0.06 & $0.32^{\mathrm{b}}$ & -0.25 \\
\hline
\end{tabular}

FA intake (expressed as per cent total energy) and adipose tissue content of $14: 0,16: 0$ or 18:0 (mol\%). The FA 15:0 is solely derived from diet, mainly from dairy sources, and should represent a major component of saturated FA intake. Although 15:0 could not be measured, for technical reasons, in adipose tissue $\mathrm{TG}$, values were assessed in plasma NEFA. For other saturated FAs, there were correlations between proportion in plasma NEFA and in adipose tissue TG (e.g. 14:0, $r=0.50, p=0.001 ; 18: 0, r=$ $0.38, p<0.01)$. There were no correlations between plasma 15:0 and adipose tissue proportions of $14: 0$ or 18:0, implying a predominantly non-dietary origin for these FAs.

\section{Discussion}

We found that small adipocyte size was related to peripheral IS, independently of BMI. We also found that the 14:0 and 18:0 content of the adipocyte TG was strongly correlated with IS and smaller fat cells, which has not been previously reported.

The relationship between cell size and IS that we observed is in line with a prospective study in Pima Indians [2], but contrary to the findings of McLaughlin et al., who used a cell-size profiling method and showed that, after controlling for obesity, there was a predominance of large adipocytes in an insulin-sensitive subgroup [30]. Our study is not directly comparable as we looked at lean as well as obese individuals, and we used a mean adipocyte value instead of a cell size distribution. This could mean that we missed subtle differences in cell size distribution. However, there is some consistency in our findings: McLaughlin et al. [30] showed a lower mRNA expression of genes concerned with adipocyte differentiation, including PPARG1 and PPARG2, in adipose tissue from insulin-resistant people. We also found this, although in our data the relationship with IS/resistance was lost after controlling for BMI or mean adipocyte size. Further studies using a variety of cell-sizing methods would be needed to explore these issues fully.

Not only is there a relationship between adipocyte size and whole-body insulin resistance, but larger adipocytes are themselves more insulin-resistant in vitro. Again, this has been recognised for many years in both humans [1, 6, 31, 32] and rodents [33], usually by comparing cells from lean and obese individuals. Even within an individual, however, smaller cells are more insulin-sensitive than are larger cells [34].

Our findings on FA composition are at first sight surprising, since saturated fat intake is generally associated with adverse metabolic health consequences. It could be that some people have a higher dietary intake of 18:0 or 14:0 and this is reflected in their adipose tissue TG [24]. We did not see any correlation between dietary saturated fat and the proportions of these FAs in adipose tissue TG, despite finding the expected correlation between adipose tissue TG 18:2 n-6 and polyunsaturated FA intake [24]. Therefore, we conclude that the relationship seen between adipose tissue 14:0 and 18:0 content, and BMI and IS, is likely to represent DNL. In line with this, we found a strong inverse relationship between expression of genes associated with DNL, and both BMI and adipocyte cell size. This is in agreement with previous studies where lower expression of $F A S N$ was seen in adipose tissue of obese individuals, despite this group having increased hepatic lipogenesis compared with the lean [13], and where lower expression of $F A S N$ was seen in adipose tissue of obese individuals irrespectively of diet [35]. Other studies have not found any clear evidence that DNL is more active in adipose tissue obtained from obese individuals [36], even following a high carbohydrate diet [12]. In contrast to our findings, Berndt et al. [14] recently found increased FASN expression in the adipose tissue of obese compared with lean individuals. The associations they observed were much stronger in visceral fat samples, although subcutaneous adipose tissue FASN gene expression did correlate positively with percentage body fat. It is difficult to explain why these findings are different from ours.

In agreement with our findings, DGAT and FASN mRNA expression in adipose tissue have been shown to correlate strongly and positively with IS, which was increased further following treatment with the peroxisome proliferatoractivated receptor gamma agonist pioglitazone [37]. In addition, fat cell lipogenesis in vitro was shown to correlate strongly and positively with IS, both basally and after insulin stimulation [38]. In our study, IS was not independently related to DNL gene expression after controlling for BMI. BMI and cell size, however, remained strongly 
inversely correlated with DNL gene expression even after controlling for IS, suggesting that fat mass and, more likely, cell size relates directly to the regulation of adipocyte DNL.

Human adipose tissue DNL is less responsive to dietary carbohydrate than is hepatic DNL [10, 35]. Also, the increased hepatic DNL in obese individuals compared with lean is not accompanied by increases in adipose tissue lipogenic capacity [13]. Together with our results, this implies that lipogenic genes do not seem to be expressed in tandem in the liver and adipose tissue, and may even be regulated in a reciprocal fashion. Dietary composition is known to have a large influence on hepatic and adipose DNL [36]. In our study, the participants were following their habitual diet, and no correlation was seen between adipose tissue DNL gene expression and carbohydrate or fat, or indeed total energy intake (data not shown). We were thus able to isolate the relationship of DNL gene expression with metabolic features rather than to short-term dietary manipulations.

There has been much interest recently in FA ratios as markers of the activity of SCD. We found a strong correlation between IS and the adipose tissue TG 18:1 n9/18:0 ratio, but not 16:1 n-7/16:0. This is in agreement with the findings of Sjögren et al. [16]. We did not, however, see any relationship between adipose tissue $S C D$ expression and adipose tissue or plasma TG or NEFA 16:1 $n-7 / 16: 0$ and 18:1 n-9/18:0 ratios (TG and NEFA data not shown), which was not in agreement with other studies [15, 16]. This discrepancy may be due to the fact that a Western diet contains a high proportion of the FAs 16:0 and 18:1 n-9 $[18,24]$, which would obscure these simple proxy SCD activity ratios in plasma and adipose tissue. In addition, in our study abdominal adipose tissue was investigated, whereas in the study by Sjögren et al. thigh fat was studied [16]. These two fat depots are known to have different relationships with disease risk factors $[39,40]$ and different FA composition [41], and thus there may be different relationships with gene expression and certain FA ratios. In addition, our studies showed that the correlations between IS, expression of genes involved in DNL, and the proxy SCD activity ratio, 18:1 n-9/18:0, and the proxy FA elongase activity ratio, 18:0/16:0, were in fact dominated by the content of 18:0 in adipose TG. To the best of our knowledge, this has not been previously demonstrated.

We have not measured DNL in human adipose tissue directly, but we have shown that the end-products 14:0 and 18:0 are present, and correlate with expression of the genes involved in DNL. Further, dynamic, studies would be required now to follow up these observations. It would also be valuable to compare smaller and larger cells from one individual, as has been done previously [34].

The downregulation of lipogenic gene expression that we observed in larger adipocytes may be seen as 'an impairment of fat cell function', as has been suggested previously [38]. However, we believe a more likely explanation is that we are observing a physiological adaptation to prevailing conditions, helping to prevent uncontrolled lipid storage from dietary sources other than FAs. It could also be that the IS of smaller adipocytes allows insulin to stimulate DNL, and that this stimulation is reduced in larger, more insulin-resistant cells. Thus, larger adipocytes may downregulate lipogenic genes in order to limit expansion of the TG store and prevent a metabolically detrimental morphology.

Acknowledgements We thank J. Cheeseman for nursing assistance with the clinical studies, and M. Gilbert for her technical expertise. We thank J. Collins for providing Fig. 1. All are from the Oxford Centre for Diabetes, Endocrinology and Metabolism. This work was supported by the UK Biotechnology and Biological Sciences Research Council (grant number BB/D008123/1). L. Hodson was a Girdlers' New Zealand Health Research Council Fellow at Green College, Oxford.

Duality of interest The authors declare that there is no duality of interest associated with this manuscript.

\section{References}

1. Salans LB, Knittle JL, Hirsch J (1968) The role of adipose cell size and adipose tissue insulin sensitivity in the carbohydrate intolerance of human obesity. J Clin Invest 47:153-165

2. Weyer C, Foley JE, Bogardus C, Tataranni PA, Pratley RE (2000) Enlarged subcutaneous abdominal adipocyte size, but not obesity itself, predicts type II diabetes independent of insulin resistance. Diabetologia 43:1498-1506

3. Lundgren M, Svensson M, Lindmark S, Renström F, Ruge T, Eriksson JW (2007) Fat cell enlargement is an independent marker of insulin resistance and 'hyperleptinaemia'. Diabetologia 50:625-633

4. Schneider BS, Faust IM, Hemmes R, Hirsch J (1981) Effects of altered adipose tissue morphology on plasma insulin levels in the rat. Am J Physiol 240:E358-E362

5. Gliemann J, Vinten J (1974) Lipogenesis and insulin sensitivity of single fat cells. J Physiol 236:499-516

6. Smith U (1971) Effect of cell size on lipid synthesis by human adipose tissue in vitro. J Lipid Res 12:65-70

7. Czech MP (1976) Cellular basis of insulin insensitivity in large rat adipocytes. J Clin Invest 57:1523-1532

8. DiGirolamo M, Howe MD, Esposito J, Thurman L, Owens JL (1974) Metabolic patterns and insulin responsiveness of enlarging fat cells. J Lipid Res 15:332-338

9. Letexier D, Pinteur C, Large V, Frering V, Beylot M (2003) Comparison of the expression and activity of the lipogenic pathway in human and rat adipose tissue. J Lipid Res 44:2127-2134

10. Diraison F, Yankah V, Letexier D, Dusserre E, Jones P, Beylot M (2003) Differences in the regulation of adipose tissue and liver lipogenesis by carbohydrates in humans. J Lipid Res 44:846-853

11. Strawford A, Antelo F, Christiansen M, Hellerstein MK (2004) Adipose tissue triglyceride turnover, de novo lipogenesis, and cell proliferation in humans measured with ${ }^{2} \mathrm{H}_{2} \mathrm{O}$. Am J Physiol Endocrinol Metab 286:E577-E588

12. Minehira K, Vega N, Vidal H, Acheson K, Tappy L (2004) Effect of carbohydrate overfeeding on whole body macronutrient metabolism and expression of lipogenic enzymes in adipose tissue of lean and overweight humans. Int J Obes Relat Metab Disord 28:1291-1298 
13. Diraison F, Dusserre E, Vidal H, Sothier M, Beylot M (2002) Increased hepatic lipogenesis but decreased expression of lipogenic gene in adipose tissue in human obesity. Am J Physiol Endocrinol Metab 282:E46-E51

14. Berndt J, Kovacs P, Ruschke K et al (2007) Fatty acid synthase gene expression in human adipose tissue: association with obesity and type 2 diabetes. Diabetologia 50:1472-1480

15. Risérus U, Tan GD, Fielding BA et al (2005) Rosiglitazone increases indexes of stearoyl-CoA desaturase activity in humans: link to insulin sensitization and the role of dominant-negative mutation in peroxisome proliferator-activated receptor-gamma. Diabetes 54:1379-1384

16. Sjögren P, Sierra-Johnson J, Gertow K et al (2008) Fatty acid desaturases in human adipose tissue: relationships between gene expression, desaturation indexes and insulin resistance. Diabetologia 51:328-335

17. Chong MF, Hodson L, Bickerton AS et al (2008) Parallel activation of de novo lipogenesis and stearoyl-CoA desaturase activity after $3 \mathrm{~d}$ of high-carbohydrate feeding. Am J Clin Nutr 87:817-823

18. Garaulet M, Hernandez-Morante JJ, Lujan J, Tebar FJ, Zamora S (2006) Relationship between fat cell size and number and fatty acid composition in adipose tissue from different fat depots in overweight/obese humans. Int J Obes (Lond) 30:899-905

19. Tan GD, Fielding BA, Currie JM et al (2005) The effects of rosiglitazone on fatty acid and triglyceride metabolism in type 2 diabetes. Diabetologia 48:83-95

20. Chen HC, Farese RV Jr (2002) Determination of adipocyte size by computer image analysis. J Lipid Res 43:986-989

21. Smith U, Sjöström L, Björntorp P (1972) Comparison of two methods for determining human adipose cell size. J Lipid Res 13:822-824

22. Pfaffl MW (2001) A new mathematical model for relative quantification in real-time RT-PCR. Nucleic Acids Res 29:e45

23. Perez-Matute P, Neville MJ, Tan GD, Frayn KN, Karpe F (2009) Transcriptional control of human adipose tissue blood flow. Obesity. doi:10.1038/oby.2008.606

24. Hodson L, Skeaff CM, Fielding BA (2008) Fatty acid composition of adipose tissue and blood in humans and its use as a biomarker of dietary intake. Prog Lipid Res 47:348-380

25. Evans K, Burdge GC, Wootton SA, Clark ML, Frayn KN (2002) Regulation of dietary fatty acid entrapment in subcutaneous adipose tissue and skeletal muscle. Diabetes 51:2684-2690

26. Bickerton AS, Roberts R, Fielding BA et al (2007) Preferential uptake of dietary Fatty acids in adipose tissue and muscle in the postprandial period. Diabetes 56:168-176

27. Matthews DR, Hosker JP, Rudenski AS, Naylor BA, Treacher DF, Turner RC (1985) Homeostasis model assessment: insulin resistance and beta-cell function from fasting plasma glucose and insulin concentrations in man. Diabetologia 28:412-419
28. Belfiore F, Iannello S, Volpicelli G (1998) Insulin sensitivity indices calculated from basal and OGTT-induced insulin, glucose, and FFA levels. Mol Genet Metab 63:134-141

29. Alberti KG, Zimmet PZ (1998) Definition, diagnosis and classification of diabetes mellitus and its complications. Part 1: diagnosis and classification of diabetes mellitus provisional report of a WHO consultation. Diabet Med 15:539-553

30. McLaughlin T, Sherman A, Tsao P et al (2007) Enhanced proportion of small adipose cells in insulin-resistant vs insulinsensitive obese individuals implicates impaired adipogenesis. Diabetologia 50:1707-1715

31. Salans LB, Bray GA, Cushman SW et al (1974) Glucose metabolism and the response to insulin by human adipose tissue in spontaneous and experimental obesity. Effects of dietary composition and adipose cell size. J Clin Invest 53:848-856

32. Davidson MB (1975) Insulin sensitivity of the large human adipocyte in vitro. Diabetes 24:1086-1093

33. Olefsky JM, Reaven GM (1975) Effects of age and obesity on insulin binding to isolated adipocytes. Endocrinology 96:1486-1498

34. Franck N, Stenkula KG, Öst A, Lindström T, Strålfors P, Nystrom FH (2007) Insulin-induced GLUT4 translocation to the plasma membrane is blunted in large compared with small primary fat cells isolated from the same individual. Diabetologia 50:1716-1722

35. Hudgins LC, Baday A, Hellerstein MK et al (2008) The effect of dietary carbohydrate on genes for fatty acid synthase and inflammatory cytokines in adipose tissues from lean and obese subjects. J Nutr Biochem 19:237-245

36. Schutz Y (2004) Concept of fat balance in human obesity revisited with particular reference to de novo lipogenesis. Int $\mathrm{J}$ Obes Relat Metab Disord 28(Suppl 4):S3-S11

37. Ranganathan G, Unal R, Pokrovskaya I et al (2006) The lipogenic enzymes DGAT1, FAS, and LPL in adipose tissue: effects of obesity, insulin resistance, and TZD treatment. J Lipid Res 47:2444-2450

38. Hoffstedt J, Förster D, Löfgren P (2007) Impaired subcutaneous adipocyte lipogenesis is associated with systemic insulin resistance and increased apolipoprotein B/AI ratio in men and women. J Intern Med 262:131-139

39. Kissebah AH, Vydelingum N, Murray R et al (1982) Relation of body fat distribution to metabolic complications of obesity. J Clin Endocrinol Metab 54:254-260

40. Azuma K, Heilbronn LK, Albu JB, Smith SR, Ravussin E, Kelley de (2007) Adipose tissue distribution in relation to insulin resistance in type 2 diabetes mellitus. Am J Physiol Endocrinol Metab 293:E435-E442

41. Phinney SD, Stern JS, Burke KE, Tang AB, Miller G, Holman RT (1994) Human subcutaneous adipose tissue shows sitespecific differences in fatty acid composition. Am J Clin Nutr 60:725-729 